\title{
ASSESSING BUSINESS AGILITY: A Multi-Industry Study in The Netherlands
}

\author{
Marcel van Oosterhout \\ Eric Waarts \\ Jos van Hillegersberg \\ RSM Erasmus University \\ The Netherlands
}

\begin{abstract}
This study reports on a cross-industry analysis of the current drivers for agility and agility gaps, which companies are facing in four industry sectors in the Netherlands. A framework was constructed to measure the gaps between the current level of business agility and the required level of business agility. The questionnaire and in-depth interviews reveal that today's businesses lack the agility required to quickly respond to largely unanticipated changes. The paper presents rankings of generic and sector-specific agility gaps. These show that although some generic drivers exist, key drivers are very different across industry sectors.
\end{abstract}

\section{INTRODUCTION}

\subsection{Background}

It has been stated (Preiss et al. 1996) that the current highly dynamic business environment increasingly requires businesses to adjust and act swiftly, in other word to be agile. As a result, the concept of agility receives growing attention. Numerous books and articles have appeared that attempt to define business agility. Academic literature and the professional press have discussed the topic by reporting on recent unexpected threats to businesses such as terrorism, unanticipated regulations, or sudden market changes, and how agility can help to overcome these. Several consultancies and ICT vendors have made helping organizations to achieve agility their key business strategy (e.g., IBM's "On-Demand" strategy and HP's "Adaptive Enterprise" strategy). They 
provide a variety of organizational and technical solutions that should help to achieve the proper level of agility to handle unexpected waves of change.

However, as was clearly shown in a panel discussion on the agile enterprise at the recent CIO Summit at Massachusetts Institute of Technology (Schrage 2004), there is by far no consensus as to what exactly agility is, nor on how one could achieve agility. Very few studies have attempted to empirically study the need for agility. What are factors that drive the need and what is the relative importance of these factors? Moreover, research that assesses the current level of agility is scarce. The few studies we have identified with this aim are usually limited in their sector focus (usually manufacturing) and research method (usually only a questionnaire or single case study). This paper aims to resolve the current confusion about business agility, to develop a framework for analyzing agility, and to apply and test the framework in four important business sectors (mobile telecom, finance, utilities and logistics) by using a comprehensive multiple method approach for data collection (multiple surveys and in-depth interviews).

\subsection{Research Questions and Approach}

The overall research question of this paper is: What are the key internal and external drivers where business lacks the necessary level of agility?

To address this question, we will subsequently investigate the following subquestions:

- What is agility and how is it different from the traditional concept of flexibility?

- What are the internal and external drivers that may require agility?

- For which drivers does today's business lack the required agility?

- What are the enablers that can provide agility?

Our approach is to first develop a definition of business agility (section 2). Based on the literature, we develop a conceptual model on drivers, enablers, and gaps for business agility (section 3). We selected a combination of quantitative (survey) and qualitative (interview) research methods to analyze the constructs in the framework (section 4). Based on this data, the key drivers for business agility and the main agility gaps are determined (section 5). Next, using qualitative data collected in interviews, we explore the enablers, disablers, and best practices for creating agility in the organization and business network (section 6). Finally we explore main conclusions, limitations and future research directions (section 7).

\section{WHAT IS AGILITY?}

\subsection{Definition of Agility}

Even though much has been said and written on the subject, a consensus on a definition of agility has not yet emerged. First, the key commonalities and differences 
in concepts and definitions will be discussed; subsequently a definition for this study will be formulated. The Agility Forum distinguishes four strategic dimensions: enriching customers, cooperating to compete, leveraging resources, and mastering change for defining business agility. These terms often reappear in definitions proposed by others. It is seen as the way to cope with the competition, business practices, and corporate structures of the $21^{\text {sl }}$ century. Companies must be proactive and must view change as normal and as an opportunity.

\section{Definitions of Business Agility}

The ability of an organization to thrive in a continuously changing, unpredictable business enviromment (Dove 2001)

The ability of an enterprise to develop and exploit its inter-and intra-organizational capabilities (Hooper et al. 2001)

Agility is primarily concerned with the ability of enterprises to cope with unexpected changes, to survive unprecedented threats from the business environment, and to take advantage of changes as opportunities (Sharifi and Zhang 2000)

Agility is considered as being able to deal with changes that are, to a large extent, unpredictable, while the response is more innovative (Whadhwa and Roa 2003)

Agility is the successful exploration of competitive bases (speed, flexibility, innovation pro-activity, quality, and profitability) through the integration of reconfigurable resources, and best practices in a knowledge-rich environment to provide customer-driven products and services in a fast changing market environment (Ramasesh et al. 2001)

Agility is the ability to thrive in a competitive environment of continuous and unanticipated change and to respond quickly to rapidly changing, fragmenting global markets that are served by networked competitors with routine access to a worldwide production system and are driven by demand for high-quality, highperformance, low-cost, customer-configured products and services (Goldman et al. 1995)

From the definitions in the box, some general aspects do come forward. Agility is a way to cope with (to a large extent) unforeseen changes. Furthermore, how a company can deal with changes is important: is it able to respond in a timely manner and with ease? Response is innovative rather than pre-engineered. Moreover, it is important to note that agility is relevant on two different levels: the enterprise level and the business network level. These two levels naturally interact. When the network around a company is agile, it will require the company to be agile too. Second, when the network is agile, 
it will facilitate the enterprise to be agile. In a situation where the enterprise is the only agile link in the network, this will often inhibit the company from reacting appropriately.

\subsection{Flexibility Versus Agility}

Dealing with change has always been an important issue in organizations. In areas where change is predictable and the response required can be largely predetermined, organizations need to be flexible. To a large degree, flexibility can be engineered into the organization's processes and IT systems. Changing the parameters in a traditional ERP-package to accommodate for the occurrence of a predictable change is a good example of this. In other cases, changes can arise unexpectedly and the required response is more difficult to predetermine. In such cases, flexibility cannot easily be engineered into the organizational processes and systems. Being able to react quickly to such changes requires a new level of flexibility, which we refer to as agility. This is in line with common definitions of agility

Taking all of these considerations into account, we define agility in this study as follows:

Business agility is being able to swiftly and easily change businesses and business processes outside the normal level of flexibility to effectively deal with highly unpredictable external and internal changes

If businesses find it difficult to cope with major changes, which go beyond their normal level of flexibility, they are faced with an agility gap. The two terms and the way we analyze them in this study are presented in Figure 1.

\section{CONCEPTUAL FRAMEWORK}

In this section, the conceptual framework and underlying elements are explained.

\subsection{Framework Introduction}

Building on the work by Sharifi and Zhang (1999), we constructed a framework to analyze business agility in detail (see Figure 2). Factors that are taken into account are the general external environment factors (politics, economics, society, and technology) and the four key agility dimensions (Goldman et al. 1991): cooperating to enhance competitiveness, enriching the customer, mastering change and uncertainty, and leveraging the impact of people and information. In addition, in line with Mason-Jones and Towill (1999), Van Hoek et al. (2001), and Yusuf et al. (2004), we explicitly regard companies not as isolated entities but as part of a business network that affects the level of agility of the individual company. $A$ business network-wide strategy to cope with turbulence in the business environment is considered eminent for all parties in the network. Therefore, we have added the business network dimension to the original model of Sharifi and Zhang (1999). 


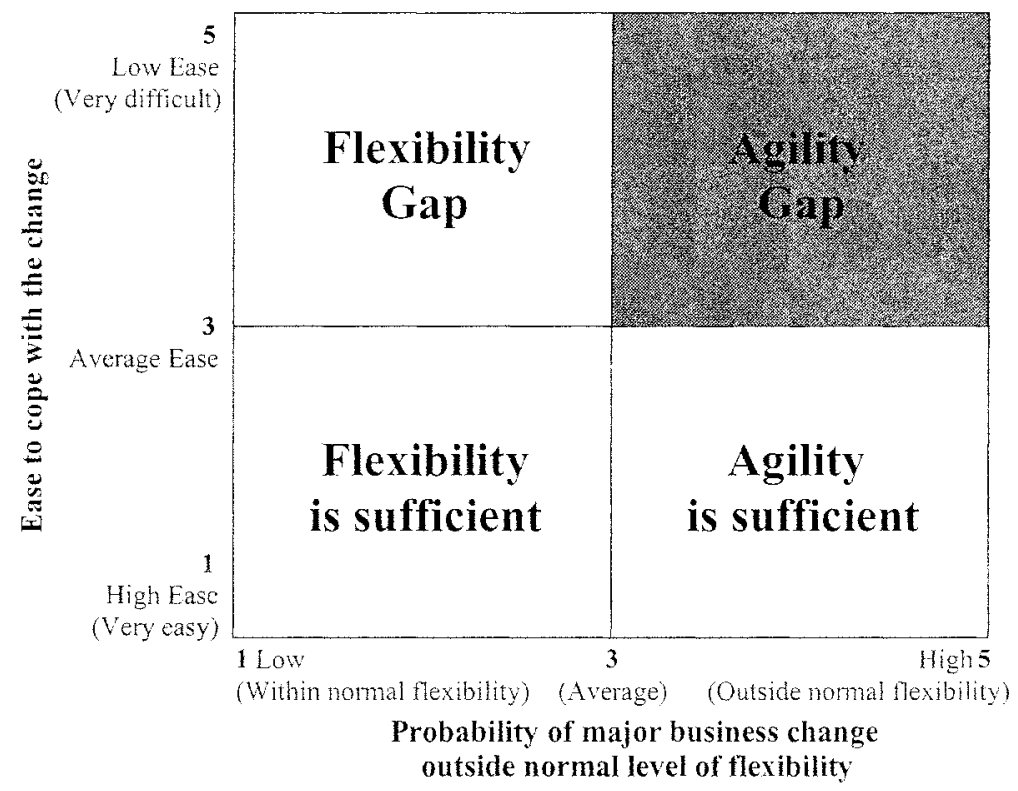

Figure 1. Flexibility Versus Agility

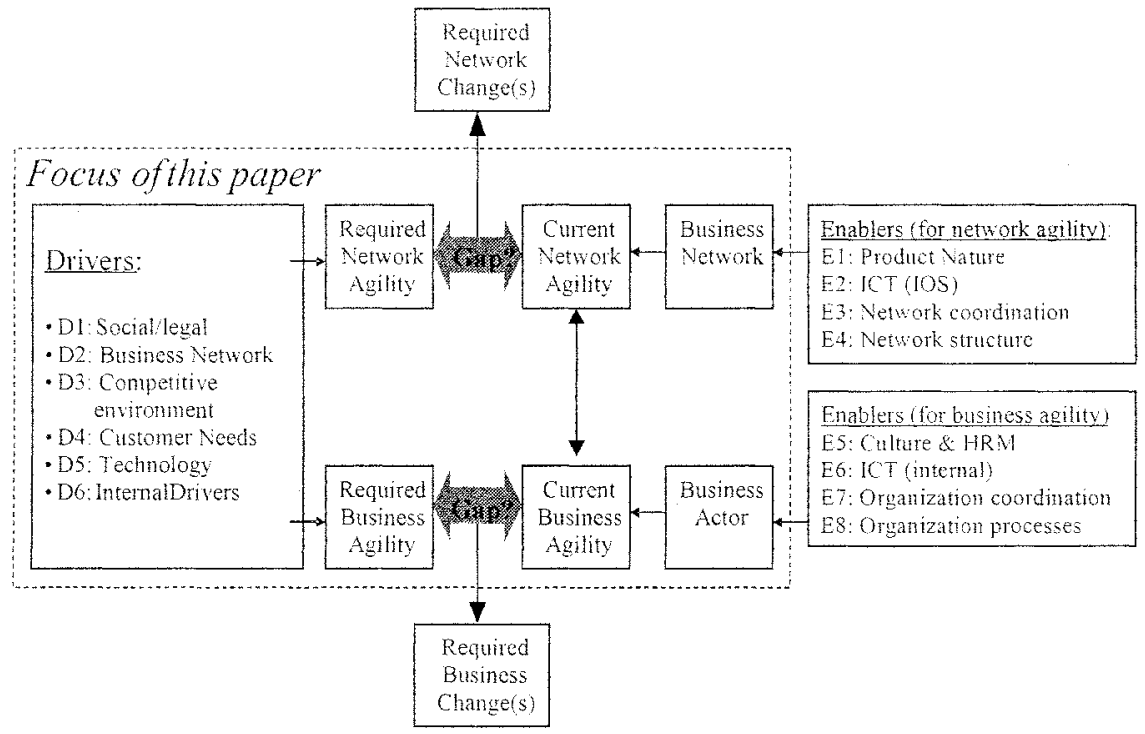

Figure 2. Research Model for Studying Business and Network Agility 
Figure 2 shows our research model. It consists of three interrelated elements

- Agility drivers: Agility drivers are internal or external factors influencing the required level of business agility. In our model, we have identified six categories of drivers. Agility drivers require businesses to adjust.

- Agility gaps: Agility gaps arise when the firm has difficulty in meeting the required level of agility for changing from one state to another in a timely and cost effective manner.

- Agility enablers: Agility enablers are a means for a business to enhance business agility. In our model, these enablers are presented in four categories. We also identify enablers for network agility.

Although our empirical study encompasses all three elements, in this paper we will focus on the identification of important agility drivers and agility gaps. We will briefly reflect on the means to enable agility at the end of this paper.

\subsection{Agility Drivers}

In this study, two broad categories of agility drivers are distinguished, external and internal agility drivers. External agility drivers are grouped in the following domains of external change: social or legal, business network, the competitive environment, changes in customer needs, and technology. The internal agility drivers consist of three types: (1) performance indicators, (2) information technology, and (3) mergers and acquisitions. Internal drivers are internally initiated changes (e.g., a new strategy, a takeover, etc.) that require the organization to adapt. Although initially unpredictable internal drivers may sound like a paradox, in many cases large corporations have indicated that agility gaps emerged as a result of a new corporate strategy, newly defined performance indicators, a large merger or takeover, or a organization-wide IT system implementation. Table 1 presents both external and internal driver categories and examples of potential drivers within the categories, used in this study. All are based on earlier studies on agility and related topics.

\section{METHODOLOGY}

\subsection{Research Methods}

Figure 3 gives an overview of the research methods (and their interrelations) used within our research project on business agility in four Dutch business sectors.

The first phase in this research was a literature review and Internet research. This literature review focused on business agility and developments in four selected sectors. The literature review provided the necessary input to construct a survey. We used feedback from experts and two workshops to test and improve the survey. 
Table 1. Overview of Potential External and Internal Agility Drivers

\begin{tabular}{|c|c|c|}
\hline $\begin{array}{l}\text { Driver } \\
\text { Category }\end{array}$ & Examples of drivers & $\begin{array}{l}\text { Related literature } \\
\text { references }\end{array}$ \\
\hline $\begin{array}{l}\text { D1 } \\
\text { Social/legal }\end{array}$ & $\begin{array}{l}\text { - Deregulation } \\
\text { - Legal/political pressures } \\
\text { - Social contract changes } \\
\text { - Environmental changes and } \\
\text { emergencies/disasters }\end{array}$ & $\begin{array}{l}\text { D'Aveni } 1999 \\
\text { Gartner Research } 2003 \\
\text { Sharifi and Zhang } 1999 \\
\text { Kaptein and Wempe } 2002\end{array}$ \\
\hline $\begin{array}{l}\mathrm{D} 2 \\
\text { Business } \\
\text { Network }\end{array}$ & $\begin{array}{l}\text { - Mergers } \\
\text { - Takeovers } \\
\text { - Consolidations } \\
\text { - Partnerships }\end{array}$ & $\begin{array}{l}\text { Best } 2001 \\
\text { Porter } 1980 \\
\text { Van Weele } 2001\end{array}$ \\
\hline $\begin{array}{l}\text { D3 } \\
\text { Competitive } \\
\text { Environment }\end{array}$ & $\begin{array}{l}\text { - Increasing pressure on cost } \\
\text { - Responsiveness of competitors to } \\
\text { changes } \\
\text { - Increasing rate of change in } \\
\text { product models and product } \\
\text { lifetime shrinkage } \\
\text { - Threat of entry of new players }\end{array}$ & $\begin{array}{l}\text { Goldman et al. } 1995 \\
\text { Porter } 1980 \\
\text { Sharifi and Zhang } 1999 \\
\text { Swafford } 2003 \\
\text { Volberda } 1999\end{array}$ \\
\hline $\begin{array}{l}\text { D4 } \\
\text { Customer } \\
\text { Needs }\end{array}$ & $\begin{array}{l}\text { - Demand for customized products } \\
\text { and services } \\
\text { - Need for quicker delivery time } \\
\text { and time to market } \\
\text { - Increasing expectation of quality } \\
\text { - Sudden changes in order quantity } \\
\text { and specification } \\
\text { - Shifts in customer tastes }\end{array}$ & $\begin{array}{l}\text { Da Silveira et al. } 2001 \\
\text { Goldman et al. } 1995 \\
\text { Maskell } 2001 \\
\text { Robben and Overstraeten } \\
1999 \\
\text { Sharifi and Zhang } 1999 \\
\text { Swafford } 2003\end{array}$ \\
\hline $\begin{array}{l}\text { D5 } \\
\text { Technology }\end{array}$ & $\begin{array}{l}\text { - Introduction of wireless } \\
\text { connectivity } \\
\text { - Emerging technologies to easily } \\
\text { connect to partners' information } \\
\text { systems (applications integration/ } \\
\text { middleware/messaging) } \\
\text { - Increasing number of viruses }\end{array}$ & $\begin{array}{l}\text { Gartner Research } 2003 \\
\text { Swafford } 2003 \\
\text { Vervest and Dunn } 2000\end{array}$ \\
\hline $\begin{array}{l}\text { D6 } \\
\text { Internal }\end{array}$ & $\begin{array}{l}\text { - Changes in customer loyalty and } \\
\text { other performance indicators } \\
\text { - Information technology } \\
\text { implementation } \\
\text { - Mergers and acquisitions }\end{array}$ & Gartner Research 2003 \\
\hline
\end{tabular}




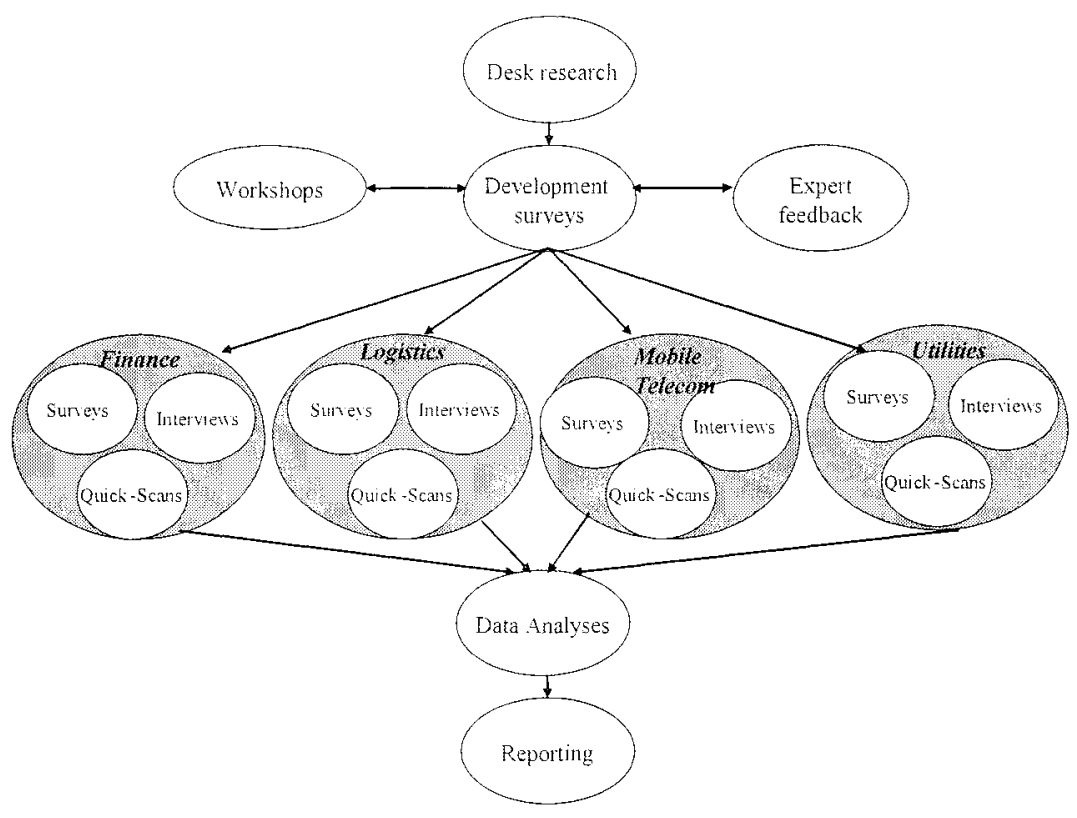

Figure 3. Research Setup

We focused on four sectors for collecting empirical data (see section 4.3). We have chosen different methods of data gathering in order to provide a rich picture on the topic. We have gathered quantitative data via online surveys. This was complemented with indepth qualitative data, gathered via interviews with executives and via workshops. The results were validated by interviews with sector experts and a (shorter) quick-scan survey among managers.

\subsection{Questionnaire}

We constructed a questionnaire containing 99 items in four parts covering the various elements of our research framework. A copy of the full questionnaire can be obtained from the researchers. The survey was hosted on a Web site in order to get a quick response. The digital output of the surveys was directly read into a database. Parts B (65 items over five subparts) and C (34 items over three subparts) of the survey were built up dynamically. In part $B$, various agility drivers were presented to the respondent. To establish whether a driver demands a company to change in the near future, each suggested driver in the survey had to be scored on a five-point Likert scale. If the "probability of major business change outside the normal level of flexibility" due to a certain driver was high (score 4 or 5 ), a second question was posed regarding the "ease to cope with the required business change" in the business network (also on a five-point 
Likert scale). If this question was answered with "very difficult" (score 4 or 5), this driver creates an agility gap (see Figure 1). In the final part of the questionnaire, part $\mathrm{D}$, for the top 10 agility gaps, open questions were generated. For each agility gap, the respondent was asked to elaborate on the bottleneck(s) and measures taken with regard to the agility gap. In this way, the questionnaire generated both quantitative data on the agility gaps as well as qualitative data on agility bottlenecks and enablers.

\subsection{Selection of the Sectors Analyzed}

We have chosen not to perform a broad random survey among businesses in all kinds of sectors, but to focus on a limited set of business sectors. With this approach, we can get deeper insight into the factors determining change and the difficulties firms have coping with these changes. In particular, we have analyzed four sectors in the Dutch business community, each of which can be considered to be changing rapidly:

- Logistics (logistics service providers)

- Finance (retail banking)

- Utilities (distribution and sales of energy)

- Mobile telecom (mobile telecom operators)

We have chosen these four highly dynamic business sectors because they constitute an important segment of the total Dutch business community and they are confronted with a wide variety of internal and external drivers of change.

\subsection{Data Gathering and Research Sample}

For the interviews with executives within each sector, a sample of companies was selected. Criteria to select companies were their position in the market (top market share players, considerable size) and a number of new players were interviewed. Within each company, at least two executives were asked to fill out the survey as a basis for the indepth interviews, which were held with at least two executives. One interview was held to cover the marketing perspective of business agility (mainly with CEOs and Marketing executives) and one to cover the operations and ICT perspective (mainly with COOs, CIOs, and CTOs). The average duration of the interview was 90 to 120 minutes. The basis for the interviews was the agility gaps found in the survey and the main agility issues found in the sector research. From each interview, minutes were taken and checked for accuracy with the interviewee. Table 2 provides an overview of the research sample for the case studies.

As a validation of the results found in the surveys and interviews and to gather data from more respondents within the four sectors, a shorter, quick-scan version of the survey was sent to a random sample of company contacts in different market segments (see Table 3).

We have used SPSS to analyze the quantitative data and we have organized expert sessions to extrapolate overall findings. 
Table 2. Research Sample Case Studies

\begin{tabular}{|c|c|c|c|c|c|}
\hline Sectors & 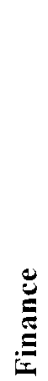 & 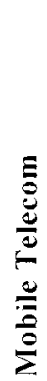 & 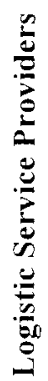 & 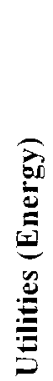 & $\bar{\sigma}$ \\
\hline $\begin{array}{l}\text { Number of companies participated in } \\
\text { interviews }\end{array}$ & 7 & 4 & 6 & 4 & 21 \\
\hline $\begin{array}{l}\text { Number of respondents filling out full } \\
\text { surveys }\end{array}$ & 10 & 11 & 8 & 8 & 37 \\
\hline Number of interviews with executives & 13 & 8 & 9 & 6 & 36 \\
\hline Expert interviews & 3 & 3 & 3 & 2 & 11 \\
\hline
\end{tabular}

Table 3. Research Sample Quick-Scan Surveys

\begin{tabular}{|l|c|}
\hline \multicolumn{1}{|c|}{ Sectors } & Quick-Scan Respondents \\
\hline Finance & 67 \\
\hline Mobile Telecom & 17 \\
\hline Logistic Service Providers & 12 \\
\hline Utilities (energy) & 6 \\
\hline Other: Industry & 12 \\
Government & 25 \\
Consumer Packaged Goods & 6 \\
ICT & 12 \\
Various & 24 \\
\hline Total & $\mathbf{1 8 1}$ \\
\hline
\end{tabular}

\subsection{Analyzing the Urgency of Agility Gaps: The Agility Gap Ratio}

In order to analyze the urgency of the various agility drivers, an agility gap ratio was calculated from the survey results. Drivers that have a high probability of change (score 4 or 5 ) and a low ease of coping (score 4 or 5 ) create an agility gap. In order to analyze the urgency of the various gaps, we calculated an agility gap ratio by using the following formula: 


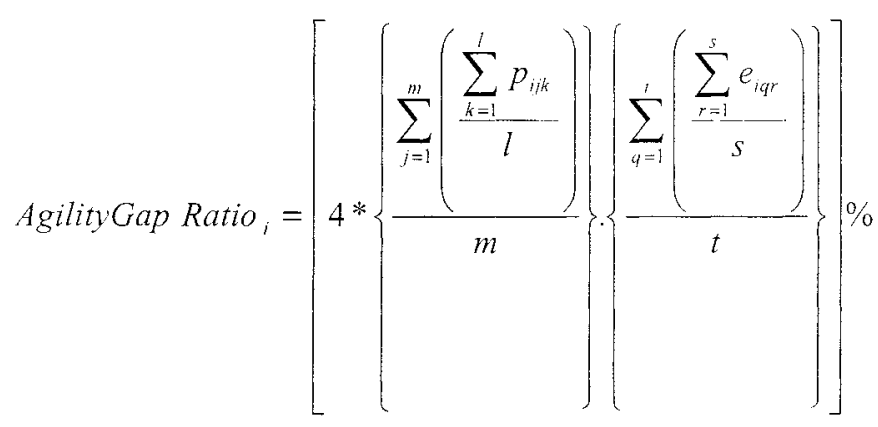

with the following meanings:

$p_{i j k} \quad$ The probability of business change, as indicated by respondent $k$, from company $j$, referring to driver $i$ (only non-blank answers have been taken into consideration)

$e_{i q r} \quad$ The degree of ease to achieve business change, as indicated by respondent $r$, from company q, referring to driver i (only non-blank answers have been taken into consideration)

i The agility driver concerned

j The company of the respondent who responded to the survey

$\mathrm{k} \quad$ The individual respondent from company $\mathrm{j}$

1 The number of respondents from company $j$

$\mathrm{m} \quad$ The number of responding companies

q The company of the respondent who responded to the survey with one or more individual respondent scoring $\mathrm{p}_{\mathrm{ijk}}$ (the probability of business change on driver i) with a high score of 4 or 5 (only if the probability of business change scored 4 or 5 a question was posed to the respondent about the ease to cope with this business change)

$r \quad$ The individual respondent from company $q$ scoring $p_{i j k}$ (the probability of business change on driver i) with a high score of 4 or 5

$s \quad$ The number of respondents from company $q$ scoring $p_{i j k}$ (the probability of business change on driver i) with a high score of 4 or 5

$t \quad$ The number of responding companies with an individual respondent scoring $p_{i j k}$ (the probability of business change on driver i) with a high score of 4 or 5 (only if the probability of business change scored 4 or 5 a question was posed to the respondent about the ease to cope with this business change) (in case of a high agility gap ratio $m=s$ )

The agility gap ratio has been scaled to a number between 0 percent (no gap at all) and 100 percent (largest gap possible). The higher the percentage, the more urgent the agility gap. 


\section{FINDINGS}

We will focus our findings on the assessment of the drivers and gaps. The results of the study reveal a number of drivers that generate generic agility gaps, present in all sectors under study, and a number of sector specific gaps.

\subsection{Generic Agility Drivers and Gaps}

We have identified agility gaps that are generic (i.e. gaps that are present in all four sectors). The top 15 generic agility gaps (with their respective driver category number) based on their average agility gap ratio are shown in Figure 4 . The values represent the average gap ratio per change driver over the four sectors analyzed.

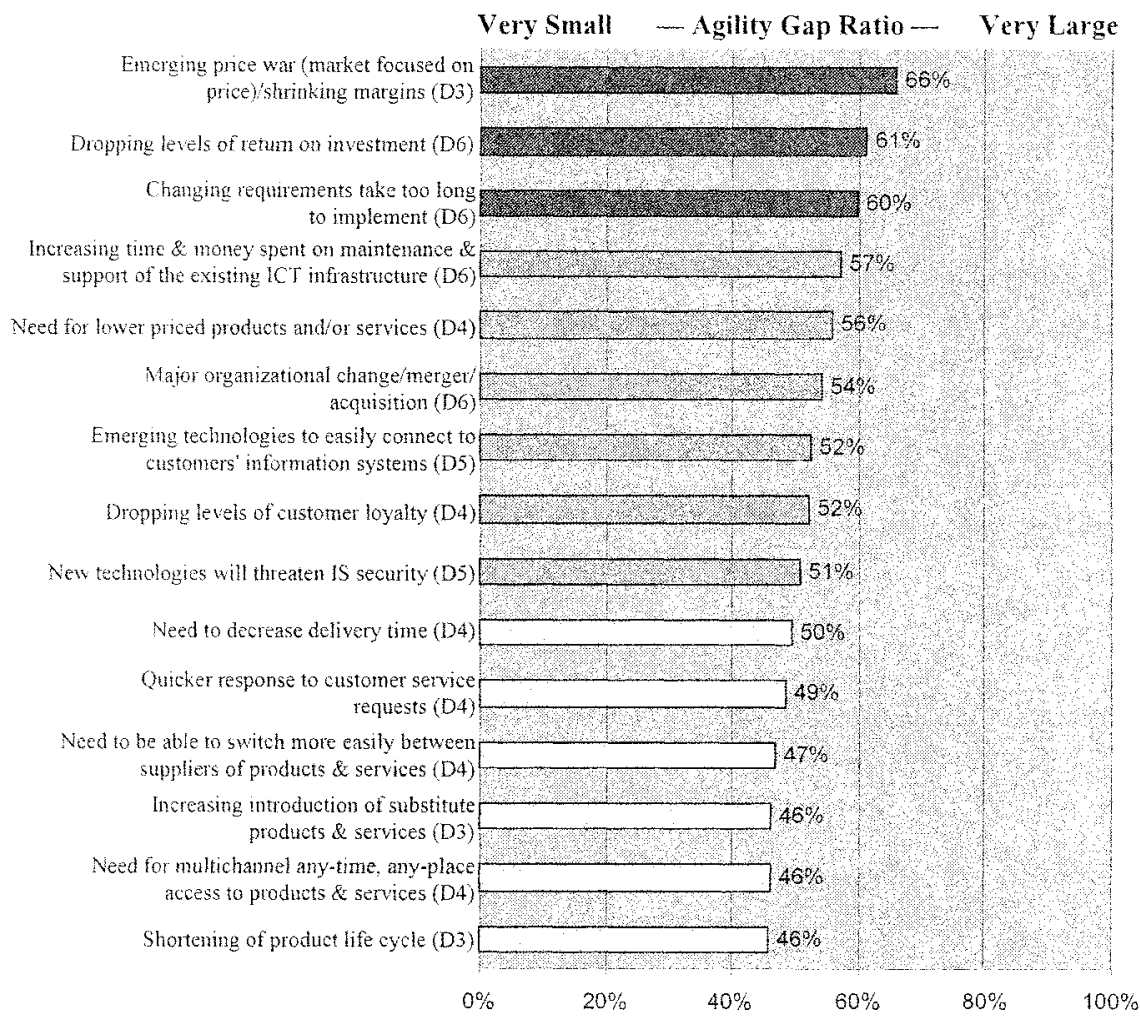

Figure 4. Overall Agility Gap Top 15 (Source: Executive Survey) 
The emerging price war and the need for lower-price products and services are influencing all sectors analyzed. Companies have a number of difficulties coping with the required changes. Lowering the price requires another way of working and influences the way companies are structured and operate. The top 15 generic agility gaps also indicate that most problems are found in the implementation of the (resulting) changing requirements in the respondent's own organization and in the business network. To a large degree, this can be explained by the existing legacy infrastructures (where increasingly more time and money are spent for maintenance and support). Figure 4 also indicates that the need for agility is not just created by unpredictable changes in the outside world. A lot of internal changes (such as mergers and acquisitions and changes in systems and procedures) require organizations to become more agile as well (four out of six drivers in the top six are internal drivers, category D6).

\subsection{Sector-Specific Agility Drivers and Gaps}

When we look at the individual sectors, we see a lot of differences and variety.

The first observation in the finance sector (Figure 5) is the fact that the price war is not the most dominant agility driver in this sector. The financial sector has to deal urgently with several high-impact regulations. Another gap occurs in meeting the need for multichannel access. These gaps seem very much related to other gaps in the upper zones. The new regulatory and multichannel demands put pressure on the huge legacy systems base. Attempts to handle these requirements increase costs. The apparent solution to outsource resources and personnel is complex and creates more gaps in dealing with this radical change in the organization.

The logistics sector (Figure 6) is confronted with a high number of high-urgency agility gaps. Due to fierce competition in the commodity services, prices are under pressure. The consolidation trend has resulted in a large number of mergers and acquisitions. Economies of scale have been achieved, but it is often a patchwork of IT and orga-

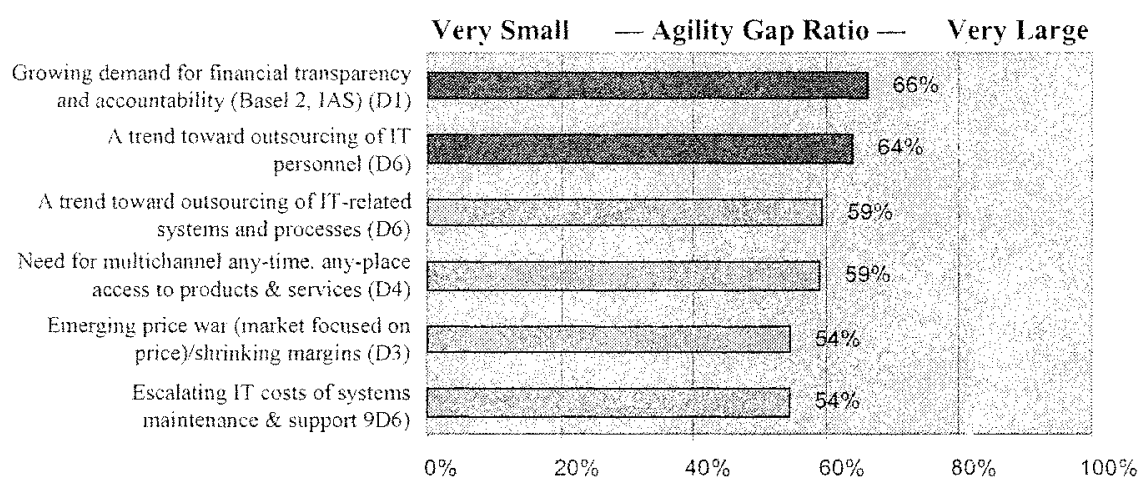

Figure 5. Overview of Most Urgent Agility Gaps for Finance Sector 


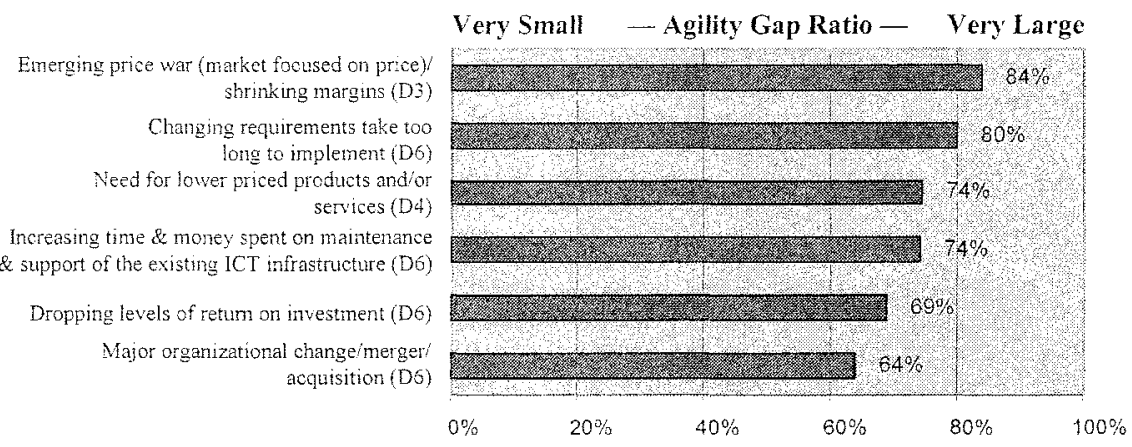

Figure 6. Overview of Most-Urgent Agility Gaps for Logistics Sector

nizational architectures. As a result of the outsourcing trend, logistics service providers have often inherited customers' logistics systems, or have to integrate tightly to those systems. Finally, the need for chain-wide tracking and tracing also requires integration to partners' information systems. Jointly, these developments have resulted in complex and heterogeneous IT architectures that need to be maintained and changed. As a result, new products, services, and regulations require substantial resources in order to be implemented. Note that the gaps related to price pressure and systems integration and adaptation are severe $(>70 \%)$.

The main gaps for the mobile telecom sector (Figure 7) seem to originate from the intensified competition. New services have resulted in customized products and services that need to be put on the market in ever-shorter time. The core systems to handle this variety of products cannot be adjusted quickly enough to implement the new requirements. Note that the gaps are not very severe $(<70 \%)$ and that potentially disruptive innovations such as wireless (WIFI) and IP telephony are only causing moderate gaps. It seems that the mobile telecom sector has, over time, developed best practices to cope with the rapid technological change.

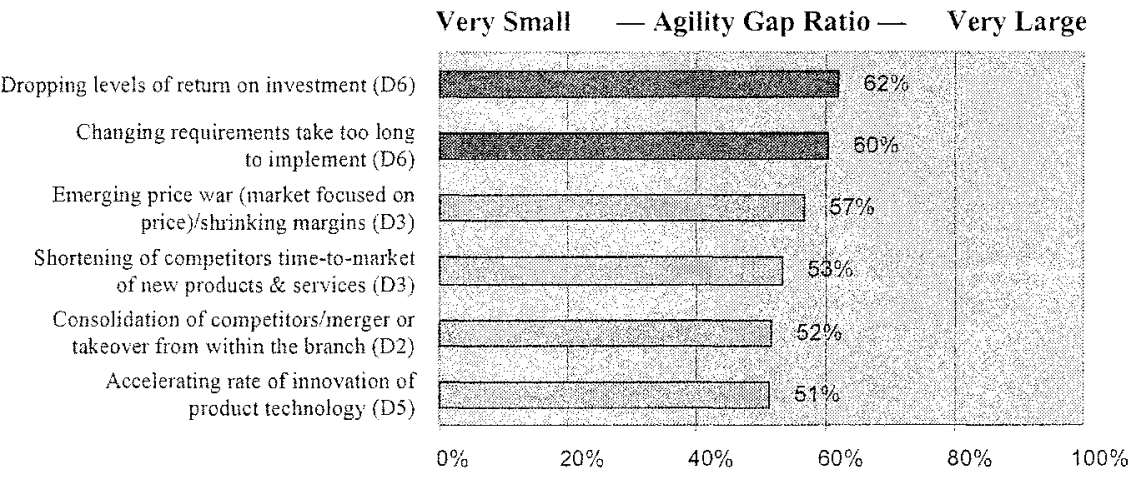

Figure 7. Overview of Most-Urgent Agility Gaps for Mobile Telecom Sector 


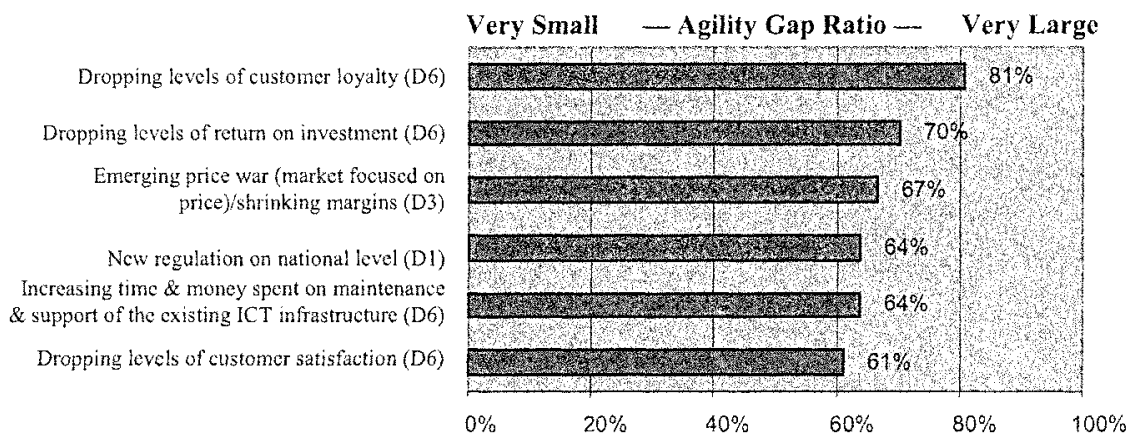

Figure 8. Overview of Most-Urgent Agility Gaps for Utilities (Energy) Sector

The utilities sector (Figure 8) is confronted with a high number of high-urgency agility gaps. These are a result of the new regulations that enforced the open market. Although this did not come as a surprise, still the impact may have been underestimated. The new phenomenon of having to worry about dropping levels of customer loyalty and customer satisfaction and a potential price war did create large gaps. IT infrastructures were never designed for processes needed in an open market. Organizational culture was more directed toward product quality than customer service.

\section{QUALITATIVE FINDINGS ON ENABLERS OF AGILITY}

Although the main focus of this paper is on the analyses of drivers and gaps for agility in four business sectors in the Netherlands, we briefly want to discuss some preliminary results of our analyses of enablers of business agility. This analysis is based on the interviews we did with executives and remarks given by respondents to the questionnaire.

What are the best practices within the four sectors in creating agility in their organization and business network? Since perceived agility needs are substantially different across the sectors, a sector-specific approach is needed in order to achieve the necessary level of business agility within sector companies. There will not be a single solution for companies to become more agile.

There are various methods to make changes in the way organizations and networks are organized. In the 1990s, the concept of business process redesign (Hammer and Champy 1993) gained popularity among managers as an approach for IT-enabled organizational change. In practice, BPR has had conflicting results. Many BPR projects failed due to poor change management, the focus on short-term gains, and the lack of attention for individuals (Attaran 2004). BPR can be used as one of the methods to make companies more agile, but other enablers, such as culture and attention to human resources management, should also be taken into account. 
The surveys and interviews revealed various best practices and enablers in creating agility in the organization and business network. These ranged from ICT, culture (change-oriented, customer-oriented), human resources (i.e., flexible employability, job rotation, cross-functional teams, new competencies), business process outsourcing, and off-shoring. Current costing systems assume static behavior. Under dynamic circumstances, they can give a very erroneous indication of prioritizing investments or expenses, which can hinder the level of agility. Executives used various approaches to improve the level of business network agility. In some sectors, executives used more soft values (such as mutual trust, shared values, expertise, and ethics) as enabling factors (e.g., in finance and utilities). Other sectors (mobile telecom and logistics) favored the combination of soft values with harder methods, such as the use of service level agreements, grading tools to audit partners, management cockpits to monitor the partner performances, etc.

Overall, executives identified culture and HRM as the key enablers for agility. Agility can be stimulated by changing reward systems, giving people room for innovation and out-of-the box thinking, and the ongoing focus on innovation and renewal. However, executives also indicated legacy problems in the area of culture and HRM which needed to be overcome (such as inherited values and ways of doing things, resistance to change, control structures, reward mechanisms).

Companies state that an agile ICT infrastructure is an important basis for business agility. With agile, one should not think of complete freedom to decentralized departments and business units to build or buy whatever system they need, nor of a rigid centralized system and inflexible IT-department. Rather, agile ICT architectures are designed for controlled change by using modern service architecture technologies and agile development processes. An agile ICT architecture is a centrally orchestrated structure based on simplification of processes and components, standardization and interoperability, scalable architectures, reusability of components, shared service centers, and flexible reconfigurable architectures. New (start-up) players in the sectors researched demonstrate the opportunities of such new ICT paradigms. Currently, due to the existence of legacy systems and a lack of standards, ICT is still felt to be a main disabler for business agility in larger organizations. Escalating IT costs of systems maintenance and support and the fact that changing requirements take too long to implement cause many companies to worry about their current ICT infrastructure. This supports the analyses of Attaran (2004, p. 595) on a number of BPR cases where "IT was the biggest barrier to rapid and radical change, because radical change required IS redesign." As stated in our definitions on flexibility versus agility, creating an agile ICT infrastructure goes beyond the engineering of flexibility by changing some parameters in an ERP package. The ICT infrastructure should be based on real-time systems with exception triggers to respond to rapid changes in customer demand and other agility drivers. Some attributes of an agile ICT infrastructure mentioned by Kruse (2002) are integrated enterprise applications using enterprise application integration, sophisticated supply chain planning and execution systems, collaborative processes and systems, seamless process automation, a fluid network of suppliers and partners, and ICT capacity sharing (e.g, on the basis of grid computing). 


\section{CONCLUSIONS AND RECOMMENDATIONS}

\subsection{Methodological Conclusions and Reflection}

The overall research objective of this paper was to come up with a framework to analyze drivers for business agility and to measure the gaps between the current level of business agility and the level of business agility needed.

We found no established measurement framework for business agility available in the literature. Therefore, we have chosen to develop a new theoretical framework based on a broad review of the literature, and to take a multimethod approach while making use of structured questionnaires and interviews to cover all important aspects. In our questionnaire, we used two questions ("probability of major business change" and "ease to cope with the change") for respondents to express their most-urgent agility gaps. We used an agility gap ratio to assess the urgency of the various gaps. In our methodology, we measured the perception of the respondents with regard to gaps; we did not objectively measure gaps on the basis of objective metrics. Future research could focus on the development of a set of such metrics and actually measuring these metrics.

We analyzed enablers and disablers for business agility via interviews and qualitative free-text remarks of respondents to the questionnaires. This provided interesting qualitative insight into the enablers and barriers for achieving agility. However, we did not construct a set of measures to objectively measure whether certain items were (perceived to be) disablers or enablers for business agility.

As stated by Whadhwa and Roa (2003), the boundaries between flexibility and agility are blurred. We have made a first attempt to develop a questionnaire to indicate the importance of agility drivers. Respondents were asked about the predictability of each category of change drivers. One could argue that a stricter difference should be made between change drivers that require more flexibility versus change drivers that require more agility. On the other hand, although the probability of a change driver might be high, the predictability of necessary changes in the business in most cases is quite low. For instance, the probability of expected changes due to government regulation in the utilities sector was high, but the predictability of necessary changes in the business and organization systems and processes was rather low. Therefore, this change driver caused a high need for agility. Given the difficulty of coping with the change, this driver posed an agility gap.

\subsection{Substantive Conclusions with Regard to Drivers and Gaps}

What are the (main) gaps between the current level of business agility and the level of business agility needed in the four sectors? Based on the survey and interviews with executives, we have come up with the top 15 agility gaps per sector analyzed. The results show a number of gaps to be present in all four sectors. Furthermore, we found a number of variations between the four sectors analyzed. The emerging price war and the need for lower-price products and services combined with fast changing customer 
requests is dramatically influencing all sectors analyzed. Companies feel severe difficulties in coping with the required changes. In many cases a totally different way of organizing the company and its business network is required. Companies are very worried about the pace at which solutions can be implemented. To a large degree, this can be explained by the existing organizational structures, cultures, and legacy infrastructures. Executives in all sectors researched feel the unpredictability of government regulation and government measures forcing them to make their processes and systems more agile. Examples of such regulations are demands for more financial transparency and accountability (e.g., Basel 2, International Financial Reporting Standards, and International Accounting Standards), deregulation measures in the utilities sector, and European Union food law regulations, containing clear requirements for traceability. Especially, the lack of implementation details and timing makes it necessary to implement the required changes in a short time frame. The results also indicate that the need for agility is not just created by unpredictable changes in the outside world; often internal changes (such as mergers and acquisitions and changes in systems and procedures) cause organizations to become more agile as well. This is reflected in the relatively large number of drivers in category D6, which scores relatively high as an agility gap.

\subsection{Further Research}

This research was conducted in the period January 2004 to August 2004. The research focused on four business sectors in the Netherlands. In order to gain more insight into the dynamics of business agility, we have two recommendations for further research. First, we recommend extending the assessment instrument with objective measurable metrics. This would be the basis for an agility barometer. This instrument would indicate, on the basis of objective measurable metrics, the level of business agility within a specific company or business network. Furthermore, such a barometer would make comparisons of companies on their agility score more feasible. Besides measuring the drivers for agility, this barometer should include measures for enablers of business agility as well. A further refinement of the instrument would be a stricter distinction between the change drivers requiring more flexibility and change drivers requiring more agility based on the level of predictability of necessary changes in the business per individual change driver.

Second, we recommend broadening the scope of the current research project to other countries. We expect that cultural and geographic differences influence the need for agility and level of business agility. An international benchmark would make it possible to compare the level of business agility and the competitive position of the Dutch business community with business communities in other countries.

\section{ACKNOWLEDGMENTS}

The authors gratefully acknowledge the financial support of Hewlett Packard for funding this researcb. Furthermore, we thank Professors Peter Vervest and Kenneth Preiss for their comments and feedback, all of the companies for their participation, and our research assistants-- Rinske 
Verwaal, Roelof Valkenier, Barbara Hertogs, and Stijn van den Bout-for their support in the field research.

\section{REFERENCES}

Attaran, M. "exploring the Relationship Between Information Technology and Business Process Reengineering," Information and Management (41), 2004, pp. 585-596.

Best, R. J. Market-Based Management: Strategies for Growing Customer Value and Profitability ( $3^{\text {rd }}$ ed.), Upper Saddle River, NJ: Prentice Hall, 2001.

D'Aveni, R. "Strategic Supremacy through Disruption and Dominance," Sloan Management Review (40:3), 1999, pp. 127-135

Da Silveira, G., Borenstein, D., and Fogliatto, F. S. "Mass Customization: Literature Review and Research Directions," International Joumal of Production Economics (72:1), 2001, pp. $1-13$.

Dove, , R. Response Ability: The Language, Structure and Culture of the Agile Enterprise, New York: John Wiley and Sons, 2001.

Gartner Research. Drive Enterprise Effectiveness: The 2003 CIO Agenda, Boston: Gartner Group, 2003.

Goldman, S., Nagel, R., and Preiss, K . Agile Competitors and Virtual Organizations, New York: Van Nostrand Reinhold, 1995.

Goldman, S., Preiss, K., Nagel, R., and Dove, R. 21 $1^{\text {st }}$ Century Manufacturing Enterprise Strategy, Iacocca Institute, Lehigh University, Bethlehem, PA, 1991.

Hammer, M., and Champy, J. Reengineering the Corporation, New York: Harper Collins, 1993.

Hooper, M. J., Steeple, D., and Winters, C. N. "Costing Customer Value: An Approach for the Agile Enterprise," International Journal of Operations and Production Management (21:5-6), 2001, pp. 630-644.

Kaptein, M., and Wempe, J. The Balanced Company, Oxford, England: Oxford University Press, 2002.

Knechel, W. R. Auditing Assurance and Risk (2 $2^{\text {nd }}$ ed.), Mason, OH: Southern Western, 2001.

Kruse, G. "IT-Enabled Lean Agility," Control, November 2002, pp. 19-22

Maskell, B. "The Age of Agile Manufacturing," Supply Chain Management: An International Joumal (6:1), 2001, pp. 5-11.

Mason-Jones, R., and Towill, D. R. "Total Cycle Time Compression and the Agile Supply Chain," International Journal of Production Economics (62), 1999, pp. 61-73.

Porter, M. E. Competitive Strategy: Techniques for Analyzing Industries and Competitors, New York: Free Press, 1980.

Preiss, K., Goldman, S. L., and Nagel, R. N. Cooperate to Compete: Building Agile Business Relationships, New York: Van Nostrand Reinhold, 1996.

Ramasesh, R., Kulkarni, S., and Jayakumar, M. "Agility in Manufacturing Systems: An Exploratory Modeling Framework and Simulation," Integrated Manufacturing Systems (12:6-7), 2001, pp. 534-548.

Robben, H., and Overstraeten, P. Competing in Changing Markets, International Survey, Universiteit Nyenrode, Breukelen, The Netherlands, 1999.

Schrage, M. "The Struggle to Define Agility," CIO Magazine, August 15, 2004 (available online at http://www.cio.com/archive/081504/schrage.html).

Sharifi, H., and Zhang, Z. "A Methodology for Achieving Agility in Manufacturing Organizations," International Journal of Operations and Production Management (20:4), 1999, pp. 496-513. 
Sharifi, H., and Zhang, Z. "A Methodology for Achieving Agility in Manufacturing Organizations: An Introduction," International Journal of Production Economics (62), 1999, pp. 7 22.

Swafford, P. Theoretical Development and Empirical Investigation of Supply Chain Agility, Unpublished Ph.D. Dissertation, Georgia Institute of Technology, Atlanta, GA, Apri1, 2003.

Van Hoek, R. I, Harrison, A., and Christopher, M. "Measuring Agile Capabilities in the Supply Chain," International Joumal of Operations and Production Management (21:1-2), 2001, pp. 126-147.

Van Weele, A. J. Purchasing and Supply Chain Management: Analysis, Planning and Practice ( $3^{\text {rd }}$ ed.), London: Thompson International, 2001.

Vervest, P., and Dunn, A. How to Win Customers in the Digital World: Total Action or Fatal Inaction, Berlin-Heidelberg: Springer-Verlag, 2000.

Volberda, H. W. Building the Flexible Firm: How to Remain Competitive, Oxford, England: Oxford University Press, 1999.

Wadhwa, S., and Rao, K. S. "Flexibility and Agility for Enterprise Synchronization: Knowledge and Innovation Management Towards Flexagility," Studies in Informatics and Control (12:2), 2003, pp. 111-128.

Yusuf, Y. Y., Gunasekaran, A., Adeleye, E. O., and Sivayoganathan, K. "Agile Supply Chain Capabilities: Determinants of Competitive Objectives," European Journal of Operational Research (159:2), December 2004, pp. 379-392.

\section{ABOUT THE AUTHORS}

Marcel van Oosterhout is a scientific researcher at the RSM Erasmus University. He has participated in many (inter)national research and consulting projects. His research interests include smart business networks, electronic business, and e-logistics. Marcel can be reached at moosterhout@rsm.nl.

Eric Waarts is Professor of Marketing at the RSM Erasmus University. His interests are concentrated on marketing, competitive behavior, innovation, and international marketing strategy. He has published a wide range of books and articles on these topics. Eric can be reached at ewaarts@rsm.nl.

Jos van Hillegersberg is an associate professor at the RSM Erasmus University. His research interests include (global) software development for e-business, ICT support for coordination of global teams, and ICT architectures. He has worked on many research and consulting projects. Jos can be reached at jhillegersberg@rsm.n1. 